\title{
Lebanese Pharmacists' Knowledge and Attitude toward Cannabis Medical Use Legality
}

\author{
Lynne H. Jaffal, Nathalie Lahoud, Salam Zein ${ }^{\mathbb{D}}$, Sanaa Awada ${ }^{\mathbb{D}}$, Dalia Khachman ${ }^{*}$ \\ Clinical and Epidemiological Research Laboratory, Faculty of Pharmacy, Lebanese University, Hadat, Lebanon
}

\section{ARTICLE INFO}

\section{Article History}

Received 02 October 2019

Accepted 25 April 2020

\section{Keywords}

Attitude

community pharmacists

knowledge

legalization

medicinal cannabis

\begin{abstract}
Medical cannabis legalization in Lebanon has been a controversial issue. No research has been done to study the aspects of knowledge and attitudes toward its prescription in Lebanon. The primary objective of this study was to assess the level of knowledge and attitude of Lebanese community pharmacists toward its legalization. The secondary objective focused on identifying the predictors of their corresponding knowledge and attitude. A cross-sectional survey was conducted using a sample of 233 Lebanese community pharmacists. A questionnaire comprising questions about sociodemographic details, knowledge, attitude, and preferences for getting information concerning medicinal cannabis was used for data collection over a period of 3 months. Four knowledge-related scores were computed, and descriptive, bivariate, and multivariate analysis was performed using SPSS version 23 (SPSS Inc., Chicago, IL, USA). About 51\% of pharmacists were considered to have a good level of knowledge. More than half of the community pharmacists had good knowledge about its uses, side effects, and interactions. Although only 44.7\% supported cannabis legalization in Lebanon, 79.4\% agreed that it should be present in prescriptions for certain indications. Moreover, associations were found between knowledge and experience, source of information, residence, and hours spent in pharmacy. Furthermore, attitude toward cannabis prescription is associated with residence, degree perceived, having patients that can benefit, and comfort to explain cannabis efficacy. Effective educational strategies should be implemented in Lebanon in order to improve knowledge regarding cannabis not only among pharmacists but the community as a whole, and thus aid in its proper use for therapeutic purposes rather than recreational uses.
\end{abstract}

(C) 2020 Dr. Sulaiman Al Habib Medical Group. Publishing services by Atlantis Press International B.V. This is an open access article distributed under the CC BY-NC 4.0 license (http://creativecommons.org/licenses/by-nc/4.0/).

\section{INTRODUCTION}

Cannabis grows profusely in the world and designates Cannabis sativa, Cannabis indica, and Cannabis ruderalis [1,2]. The major cannabinoids responsible for its action include the psychoactive $\Delta-9$ Tetrahydrocannabinol (THC), the nonpsychoactive Cannabidiol (CBD), and Cannabinol (CBN) [1]. Interestingly, THC and CBD have antagonistic effects on addiction-related behaviors. THC boosts drug use, whereas CBD has low hedonic property and impedes drug seeking [3]. CBD is generally well tolerated with a good safety profile, yet reported adverse effects may be as a result of drug-drug interactions between CBD and patients' existing medications [4].

Reviews found an association between cannabis use and development of schizophrenia, psychosis, depression, anxiety, suicide, substance dependence, and abuse for alcohol, tobacco, and illicit drugs $[5,6]$. Adverse social outcomes included increased risk of unemployment, need for welfare assistance, poorer education, and income [7-9]. Altered brain structure and function was consistently reported among cannabis users [10]. Cannabinoid hyperemesis syndrome occurs upon chronic use and motor vehicle collisions are associated with THC $[6,11,12]$. Furthermore, cannabis smoking may

"Corresponding author. Email: dalia.khachman@outlook.com Peer review under responsibility of the Dr. Sulaiman Al Habib Medical Group Data availability statement: The data that support the findings of this study are available from the corresponding author [D.K.], upon reasonable request. cause myocardial infarctions and stroke $[6,13,14]$. With all these side effects seen in recreational use, it is difficult to project them on medically long-term supervised cannabis use [15].

In 2016, cannabis remained by far the most widely used drug worldwide with 192.2 million people consuming it. Interestingly, Lebanon is one of the top five sources of cannabis resins supplying to the neighboring countries [16].

Cannabis impedes in its constituents many therapeutical benefits. It is indicated for anorexia, nausea, and vomiting associated with cancer chemotherapy [15]. It is also used to treat muscle spasticity caused by multiple sclerosis [17,18] and seizures associated with Lennox-Gastaut syndrome or Dravet syndrome [15]. These conditions, in addition to others, made cannabis legalization for medicinal use an arguable issue worldwide.

Cannabinoid formulas authorized for marketing include Marinol (AbbVie Inc., USA) and Syndros (Insys Therapeutics, Inc., USA), which contain a synthetic THC active ingredient called dronabinol. Dronabinol is indicated for anorexia and nausea and vomiting associated with cancer chemotherapy [15]. Sativex (GW Pharma Ltd, UK) is another medicinal product with nabiximols, containing almost equal amounts of THC and CBD, and has been authorized for treatment of muscle spasticity caused by multiple sclerosis $[17,19]$. Another CBDcontaining product is Epidyolex (GW Pharma (International) B.V., The Netherlands), which is used in seizures associated with LennoxGastaut syndrome or Dravet syndrome [15]. 
Under these circumstances, health care professionals' knowledge and attitude became a great concern. In $2011,90 \%$ of hospice health professionals who were familiar with the potential uses and side effects of cannabis believed that it should be legalized for palliative symptoms [19]. Similarly in 2013, Adler and Colbert [20] reported that $76 \%$ of physicians supported cannabis medicinal use. Furthermore, Minnesota pharmacists had incomplete knowledge about medical cannabis pharmacotherapy prior to its implementation in a program in 2016 and were highly interested in filling their knowledge gaps [21]. Similarly, the majority of pharmacy students in Kansas and Novi Sad lacked accurate knowledge about medicinal cannabis indications and adverse events but welcomed cannabis legalization for therapeutic purposes but not for recreational use [22,23]. The majority of general practitioners in Australia had experienced one patient enquiry regarding medicinal cannabis within 3 months in 2017, and more than half of them stated that medicinal cannabis should be available on prescription for certain indications [24]. Meanwhile, in 2019, <10\% of the members of the California Pharmacists Association mentioned that they had a professional level of knowledge about medicinal cannabis; thus they were not ready to discuss it with their patients [25].

In Lebanon, laws make harvesting, producing, trading, or holding of illicit drugs including cannabis illegal [26]. Hence, legalizing cannabis cultivation in Lebanon for medicinal purposes proceeded as a debatable issue in the past few years [27].

With the growing trend in fight for legalization in Lebanon, pharmacists are positioned to play an important role in understanding and communicating the impact of the medical use of cannabis. They are the only health professionals permitted to dispense such products. To date, however, no research has been conducted to assess the pharmacists' readiness for this critical step. To advance our understanding, we conducted this study to help identify ongoing barriers, biases, and knowledge gaps related to medical cannabis. A secondary objective was to examine the factors influencing knowledge and attitude toward its legalization.

\section{MATERIALS AND METHODS}

\subsection{Research Design and Setting}

This is a descriptive cross-sectional survey conducted to assess Lebanese community pharmacists' knowledge and attitude toward medical cannabis legalization. The study involved the participation of 233 community pharmacies across Lebanon.

\subsection{Sample Size Calculation}

A Californian study assessing pharmacists' knowledge and attitude toward medical marijuana showed that $32 \%$ had very little knowledge [25]. Thus, the minimum sample size was calculated using Epi Info software version 7.2.2.2 (Centers for Disease Control and Prevention, USA). Considering a 95\% Confidence Interval (CI) and a 6\% acceptable margin of error, a minimum of 232 participants was required.

\subsection{Study Population and Sampling Method}

Pharmacies were selected from all Lebanese areas in Beirut, Mount Lebanon, South, Nabatieh, Bekaa, and North. All Lebanese community pharmacists or undergraduates working in community pharmacies present in the pharmacies at the time of visits were eligible to participate.

\subsection{Data Collection}

Data were collected using a well-structured questionnaire administered by a well-trained pharmacist between May 10, 2019 and July 25,2019 . Oral consent was given by pharmacists and confidentiality was ensured.

\subsection{Questionnaire}

As no validated questionnaire was available, we developed a well-structured questionnaire based on extensive research about medical cannabis and on previous similar studies that shared the same objective as ours [1,21,24,28,29]. Questions were formulated in the English language and divided into three separate sections. The questionnaire was pretested using a pilot study performed prior to data collection and involved 10 participants. Hence, questions were well formulated and free from ambiguity.

The first section included the sociodemographic characteristics. Details pertaining to age, sex, place of study, educational level, year of graduation, experience information, and place of work were all obtained.

Knowledge about medical cannabis was in the second section, which comprised Yes/No questions about knowing the therapeutic effect, side effects, medical interactions of medical cannabis, and active ingredients provided in a comment.

The third section assessed community pharmacists' attitude toward medical cannabis legalization in Lebanon through a Yes/No question, dispensing preferences and impact on society. Pharmacists' desire to receive further information was also addressed.

\subsection{Data Analysis}

Data were analyzed using SPSS version 23 (SPSS Inc., Chicago, IL, USA). Descriptive analysis on all data was performed. Continuous variables were expressed as means \pm Standard Deviations (SD), whereas categorical variables were expressed in terms of frequencies and percentages.

To assess the level of knowledge of the respondents, questions were grouped into individual scores. The most important score was a global knowledge score consisting of 59 items. Others were subscores, each of which was specific to a certain aspect including medical uses (22 items), side effect (19 items), and interaction (17 items). Pharmacists' knowledge about active molecules in cannabis was the 59th item in the global knowledge score. The number and choice of items for each score depended on obtaining the best value of Cronbach's alpha, which increases the reliability of the corresponding score. Each score was further dichotomized into two categories (poor and good knowledge) according to its median.

Hence, bivariate analysis was conducted on the dichotomized knowledge scores and pharmacists' attitude toward prescription 
where independent samples $t$-test was performed for continuous independent variables and Chi-square/Fisher's exact test for categorical ones. A $p$-value $\leq 0.05$ represented a statistically significant level for the differences and associations.

A binary logistic regression was performed on the dichotomized scores and pharmacists' attitudes toward prescription to determine their predictors. All independent variables with $p<0.2$ in the bivariate analysis were enrolled in the backward regression. Omnibus tests obtained for all regressions were significantly $<0.05$, and HosmerLemshow tests were close to 1 , ensuring the adequacy of the models. All independent variables with $p<0.05$ in the regression were considered predictors of knowledge and attitude, and the size of their effect was determined using the adjusted Odds Ratio (OR) at a 95\% CI.

\section{RESULTS}

\subsection{Descriptive Analysis}

\subsubsection{Sociodemographic characteristics}

The study involved the participation of 233 community pharmacists whose sociodemographic characteristics are described in Table 1.

\subsubsection{Knowledge about medical cannabis}

Cannabis is indicated in cases of migraine and hepatitis. Migraine was the best known condition targeted by cannabis among pharmacists $(77.7 \%)$, in contrast to hepatitis, which only $14.2 \%$ of respondents knew about. Moreover, pharmacists erroneously thought that cannabis could be used to alleviate anxiety (73.8\%), depression (75.5\%), schizophrenia (42.5\%), and vertigo (30.9\%) (cannabis is not indicated for these conditions).

Euphoria was well recognized as a side effect (80.3\%). Yet, only $30.0 \%$ of pharmacists knew that diarrhea is a side effect, whereas $63.1 \%$ wrongly stated constipation as a side effect.

Cannabis interacts with many medications. Almost half of the respondents (47.2\%) were aware that fluoxetine interacts with cannabis, whereas only $9.5 \%$ mentioned that boceprevir could interact with cannabis. Moreover, about half of respondents did not know if there is interaction between cannabis and the stated medications (Note that all drugs mentioned interact with cannabis except for omeprazole.).

Interestingly, only $33.5 \%$ of pharmacists named CBD, THC, or cannabinoids as a component of cannabis. Results are presented in Figure 1.

\subsubsection{Knowledge score and subscores}

Only $35.6 \%$ were able to answer correctly more than half of the questions concerning overall knowledge, and 51.1\% had good global knowledge (26 answers and above were correct). Medical uses knowledge score had a greater frequency compared with other
Table 1 Sociodemographic characteristics $(N=233)$

\begin{tabular}{|c|c|}
\hline Characteristics & Mean \pm SD or $N(\%)$ \\
\hline \multicolumn{2}{|l|}{ Age (years) } \\
\hline $18-24$ & $50(21.5)$ \\
\hline $25-34$ & $114(48.9)$ \\
\hline $35-44$ & $31(13.3)$ \\
\hline $45-54$ & $29(12.4)$ \\
\hline $55-64$ & $9(3.9)$ \\
\hline \multicolumn{2}{|l|}{ Gender } \\
\hline Males & $129(55.4)$ \\
\hline Females & $104(44.6)$ \\
\hline \multicolumn{2}{|l|}{ Residency } \\
\hline Beirut and Mount Lebanon & $61(26.2)$ \\
\hline South & $137(58.8)$ \\
\hline Nabatieh & $15(6.4)$ \\
\hline North Lebanon & $14(6.0)$ \\
\hline Bekaa and Baalbeck/Hermel & $6(2.6)$ \\
\hline \multicolumn{2}{|l|}{ University } \\
\hline Abroad & $76(32.6)$ \\
\hline Lebanese International University & $63(27.0)$ \\
\hline Lebanese University & $60(25.8)$ \\
\hline Beirut Arab University & $28(12.0)$ \\
\hline Lebanese American University & $3(1.3)$ \\
\hline Saint-Joseph University & $3(1.3)$ \\
\hline \multicolumn{2}{|l|}{ Degree } \\
\hline Bachelor & $138(59.2)$ \\
\hline Master & $36(15.5)$ \\
\hline Pharm. D & $27(11.6)$ \\
\hline Master and Pharm. D & $14(6.0)$ \\
\hline Undergraduate & $14(6.0)$ \\
\hline $\mathrm{PhD}$ & $4(1.7)$ \\
\hline \multicolumn{2}{|l|}{ Year of graduation } \\
\hline 1981-1990 & $10(4.3)$ \\
\hline $1991-2000$ & $31(13.3)$ \\
\hline $2001-2010$ & $48(20.6)$ \\
\hline 2011-2019 & $130(55.8)$ \\
\hline Undergraduate & $14(6.0)$ \\
\hline \multicolumn{2}{|l|}{ Working hours per week (h) } \\
\hline Mean \pm SD & $55.03 \pm 24.55$ \\
\hline Minimum & 5 \\
\hline Maximum & 112 \\
\hline \multicolumn{2}{|l|}{ Experience (years) } \\
\hline Mean \pm SD & $8.57 \pm 8.11$ \\
\hline Minimum & 0.3 \\
\hline Maximum & 39 \\
\hline \multicolumn{2}{|l|}{ Source of knowledge } \\
\hline University & $114(48.9)$ \\
\hline University and personal research & $41(17.6)$ \\
\hline Personal research & $26(11.2)$ \\
\hline Information from patient & $12(5.2)$ \\
\hline News & $9(3.9)$ \\
\hline Personal experience & $8(3.4)$ \\
\hline Information from friend & $8(3.4)$ \\
\hline Didn't receive information & $7(3.0)$ \\
\hline University and patient & $5(2.1)$ \\
\hline University and patient and friend & $3(1.3)$ \\
\hline \multicolumn{2}{|l|}{ Cannabis consumption } \\
\hline Yes & $10(4.3)$ \\
\hline No & $219(94.0)$ \\
\hline Prefer not to answer & $4(1.7)$ \\
\hline
\end{tabular}


A
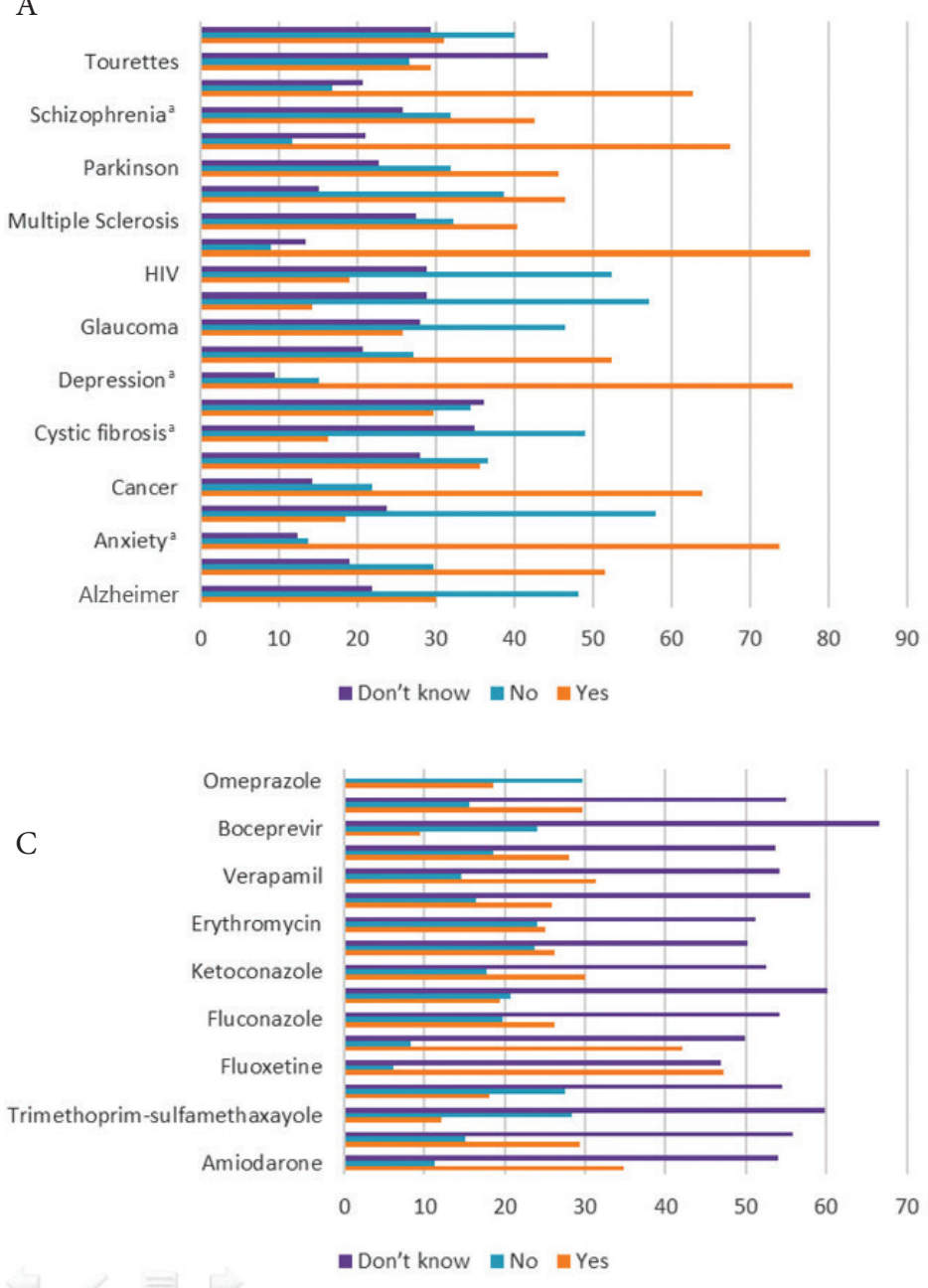

B

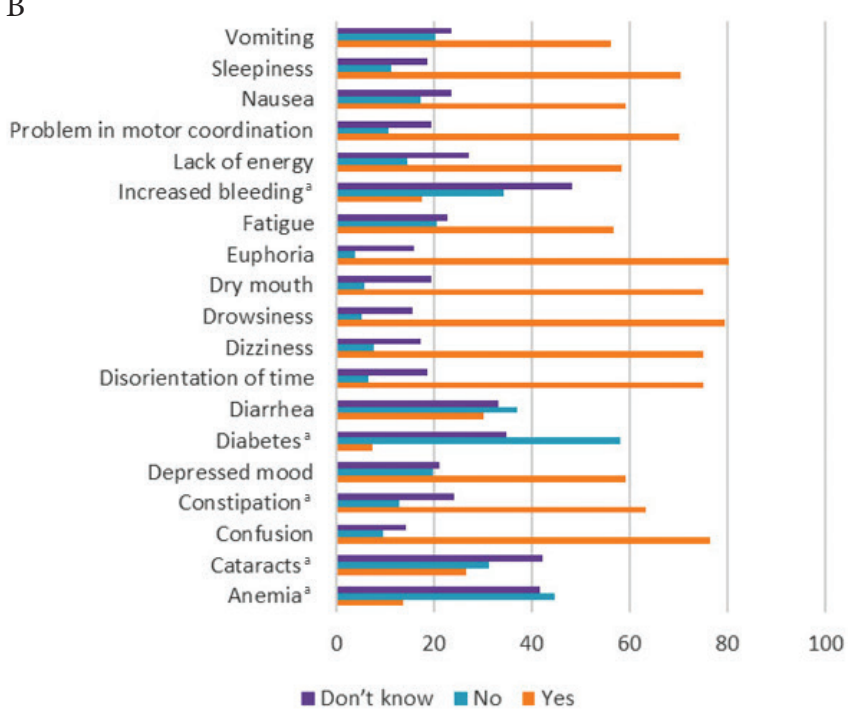

$\mathrm{D}$

Active molecule knowledge

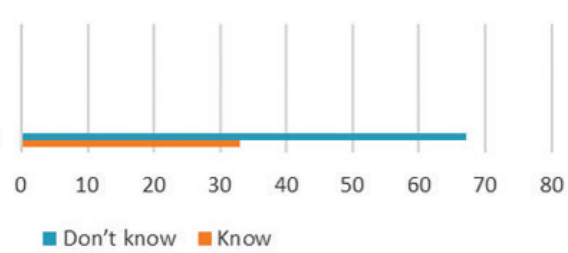

Figure $1 \mid$ Answers to questions regarding pharmacists' knowledge about medical cannabis. (A) Uses. (B) Side effects. (C) Drug interactions. (D) Active molecule knowledge. ${ }^{a}$ Not an indication nor a side effect nor having interaction.

levels, in which a score of nine/22 was obtained by $58.8 \%$ of the pharmacists (Table 2).

\subsubsection{Attitude toward medical cannabis}

Many pharmacists supported medicinal cannabis legalization (45.5\%). Furthermore, $39.1 \%$ felt assured that the benefits of cannabis outweighed its risks, and only $35.2 \%$ knew that no fatal overdose case occurred; meanwhile, $57.9 \%$ believed that the use of cannabis and its derivatives for therapeutic purposes could lead to their abuse (Table 3).

Despite the fact that $70.0 \%$ of pharmacists mentioned that they have patients who may benefit from medicinal cannabis, $42.5 \%$ believe that it will have a negative impact on the Lebanese society. Table 4 describes pharmacists' attitude toward medicinal cannabis prescription, dispensing, and knowledge acquisition.
Table 2 Descriptive analysis of each computed score

\begin{tabular}{lccccc}
\hline & \multicolumn{2}{c}{ Continuous form } & & \multicolumn{2}{c}{ Dichotomized form } \\
\cline { 2 - 3 } \cline { 5 - 6 } Score & Mean \pm SD & Median & $\begin{array}{c}\text { Poor } \\
\text { knowledge }\end{array}$ & $\begin{array}{c}\text { Good } \\
\text { knowledge }\end{array}$ \\
\hline $\begin{array}{c}\text { Global knowledge } \\
\text { score }(59 \text { items) }\end{array}$ & $25.073 \pm 10.848$ & 26 & $114(48.9)$ & $119(51.1)$ \\
$\begin{array}{c}\text { Knowledge of }>29 / 59 \\
\text { correct answers }\end{array}$ & $9 \pm 4.079$ & 9 & $96(41.2)$ & $137(58.8)$ \\
$\begin{array}{c}\text { Medical uses score } \\
(22 \text { items })\end{array}$ & $11.04 \pm 5.02$ & 13 & $114(48.9)$ & $119(51.1)$ \\
$\begin{array}{c}\text { Side effects score } \\
(19 \text { items })\end{array}$ & $4.7 \pm 4.94$ & 3 & $111(47.6)$ & $122(52.4)$ \\
$\begin{array}{c}\text { Interactions score } \\
(17 \text { items })\end{array}$ & & & $150(64.4)$ & $83(35.6)$ \\
\hline
\end{tabular}

${ }^{\mathrm{a}}$ Good knowledge if $\geq 26 / 59$ answers are correct. 
Table 3 Attitude of community pharmacists toward medical cannabis legalization

\begin{tabular}{|c|c|c|c|c|c|}
\hline $\begin{array}{l}\text { Questions to assess the attitude of community pharmacists } \\
\text { toward medical cannabis legalization }(N=233)\end{array}$ & $\begin{array}{c}\text { Do not } \\
\text { highly } \\
\text { support }\end{array}$ & $\begin{array}{l}\text { Do not } \\
\text { support }\end{array}$ & Neutral & Support & $\begin{array}{l}\text { Highly } \\
\text { support }\end{array}$ \\
\hline & \multicolumn{5}{|c|}{ Frequency $(\%)$} \\
\hline How much do you support these suggested laws? & $59(25.3)$ & $19(8.2)$ & $49(21.0)$ & $32(13.7)$ & $74(31.8)$ \\
\hline \multicolumn{6}{|l|}{ How much do you support this status? } \\
\hline $\begin{array}{l}\text { (1) The benefits of using cannabis outweigh the harms } \\
\text { and risks associated with its use }\end{array}$ & $47(20.1)$ & $28(12.0)$ & $67(28.8)$ & $48(20.6)$ & $43(18.5)$ \\
\hline $\begin{array}{l}\text { (2) There has never been a reported fatal overdose, } \\
\text { explicitly attributed to marijuana use }\end{array}$ & $91(39.1)$ & $28(12.0)$ & $32(13.7)$ & $19(8.2)$ & $63(27.0)$ \\
\hline $\begin{array}{l}\text { (3) The use of cannabis and its derivatives for therapeutical } \\
\text { purposes could cause their abuse }\end{array}$ & $52(22.3)$ & $15(6.5)$ & $31(13.3)$ & $34(14.6)$ & $101(43.3)$ \\
\hline
\end{tabular}

Table 4 Attitude toward medical cannabis prescription, dispensing, and knowledge acquisition $(N=233)$

\begin{tabular}{|c|c|c|c|}
\hline Characteristics & $N(\%)$ & Characteristics & $N(\%)$ \\
\hline \multirow{2}{*}{\multicolumn{2}{|c|}{$\begin{array}{l}\text { Should medicinal cannabis currently be available } \\
\text { on prescription for certain indications in Lebanon? }\end{array}$}} & Available types and dosage forms & $11(4.7)$ \\
\hline & & Not interested in the topic & $5(2.1)$ \\
\hline Yes & $185(79.4)$ & All & $170(73.0)$ \\
\hline No & $36(15.5)$ & Resource of information & \\
\hline Do not know & $12(5.1)$ & Ministry of Health & $68(29.2)$ \\
\hline \multirow{2}{*}{\multicolumn{2}{|c|}{$\begin{array}{l}\text { Do you have patients that may benefit from } \\
\text { cannabis? }\end{array}$}} & Order of Lebanese Pharmacists & $63(27.0)$ \\
\hline & & Ministry of Health and Order of Lebanese & $44(18.9)$ \\
\hline Yes & $163(70.0)$ & Pharmacists & \\
\hline No & $45(19.3)$ & Drug companies & $23(9.9)$ \\
\hline Do not know & $25(10.7)$ & All & $28(12.0)$ \\
\hline \multicolumn{2}{|l|}{$\begin{array}{l}\text { Do you feel comfortable explaining to your } \\
\text { patients cannabis efficacy? }\end{array}$} & $\begin{array}{l}\text { None } \\
\text { Other }\end{array}$ & $\begin{array}{l}5(2.1) \\
2(0.9)\end{array}$ \\
\hline Yes & $183(78.5)$ & Method to receive information & \\
\hline No & $41(17.6)$ & Conference & $111(47.6)$ \\
\hline Do not know & $9(3.9)$ & Online course & $36(15.5)$ \\
\hline \multirow{2}{*}{\multicolumn{2}{|c|}{$\begin{array}{l}\text { Do you feel comfortable explaining to your } \\
\text { patients cannabis side effects? }\end{array}$}} & E-mail & $34(14.6)$ \\
\hline & & All & $27(11.6)$ \\
\hline Yes & $191(82.0)$ & E-mail and conference & $8(3.4)$ \\
\hline No & $37(15.9)$ & E-mail and online course & $8(3.4)$ \\
\hline Do not know & $5(2.1)$ & None & $5(2.2)$ \\
\hline \multirow{2}{*}{\multicolumn{2}{|c|}{$\begin{array}{l}\text { Do you feel comfortable explaining to your } \\
\text { patients cannabis-drug interactions? }\end{array}$}} & Other & $4(1.7)$ \\
\hline & & Cannabis legalization will affect society & \\
\hline Yes & $180(77.2)$ & Negatively & $99(42.5)$ \\
\hline No & $44(18.9)$ & Positively & $67(28.7)$ \\
\hline Do not know & $9(3.9)$ & Neutral & $61(26.2)$ \\
\hline \multirow{2}{*}{\multicolumn{2}{|c|}{$\begin{array}{l}\text { Do you feel comfortable explaining to your } \\
\text { patients cannabis dosage forms available? }\end{array}$}} & Do not know & $6(2.6)$ \\
\hline & & Cannabis illegal consumption & \\
\hline Yes & $182(78.1)$ & Enhanced & $149(64.0)$ \\
\hline No & $42(18.0)$ & Decreased & $49(21.0)$ \\
\hline Do not know & $9(3.9)$ & No effect & $21(9.0)$ \\
\hline \multicolumn{2}{|l|}{ Dispensing preference } & Do not know & $14(6.0)$ \\
\hline Pharmacy as prescription only medication & $123(52.8)$ & Cost of purchase & \\
\hline Government regulatory body & $93(39.9)$ & Increase & $109(46.8)$ \\
\hline Pharmacy as over-the-counter & $8(3.4)$ & Decrease & $81(34.8)$ \\
\hline No preference & $9(3.9)$ & No change & $12(5.1)$ \\
\hline \multicolumn{2}{|l|}{ Support need for further clinical trials } & Do not know & $31(13.3)$ \\
\hline $\begin{array}{l}\text { Support need ror rurther cinnical trials } \\
\text { Yes }\end{array}$ & $218(93.6)$ & Obtain cannabis for abuse & \\
\hline No & $12(5.1)$ & Easier & $153(65.7)$ \\
\hline Do not know & $3(1.3)$ & Difficult & $47(20.2)$ \\
\hline \multirow{5}{*}{$\begin{array}{l}\text { Topics about medical cannabis would like to } \\
\text { learn more about } \\
\text { Medical cannabis pharmacotherapy } \\
\text { Country rules and regulations }\end{array}$} & & No effect & $26(11.1)$ \\
\hline & & Do not know & $7(3.0)$ \\
\hline & $28(12.0)$ & Expose pharmacist to danger & \\
\hline & $19(8.2)$ & Yes & $192(82.4)$ \\
\hline & (Continued) & $\begin{array}{l}\text { No } \\
\text { Do not know }\end{array}$ & $\begin{array}{c}38(16.3) \\
3(1.3)\end{array}$ \\
\hline
\end{tabular}

Table 4 Attitude toward medical cannabis prescription, dispensing, and knowledge acquisition $(N=233)$-Continued 


\subsection{Multivariate Analysis}

\subsubsection{Logistic regression on knowledge score}

Only North province was associated with pharmacists' global knowledge. These participants have a lower level of knowledge compared with those living in Beirut and Mount Lebanon by 91.8\% (OR $=0.082, p=0.02)$ (Table 5).

Receiving information from both university and research was found to be a significant predictor of knowledge of cannabis medical uses $(p=0.035)$. This knowledge was found to be improved by about two times if pharmacists received information from both university and personal research $(\mathrm{OR}=2.497$; 95\% CI, $1.064-$ $5.856)$. However, those who did not receive any information have $89.5 \%$ lower knowledge than those who obtained such information from university $(p=0.043)$.

Regarding side effect score, it was noticed that those living in North Lebanon had lower knowledge (by 94.3\%) than those living in Beirut and Mount Lebanon (OR $=0.057$; 95\% CI, 0.006-0.516; $p=0.011)$. Similarly, those who received information from news sources have less knowledge than those who received it from university by $80.9 \%(\mathrm{OR}=0.191, p=0.05)$ (Table 5$)$.

In fact, two variables showed an association with the interaction score. Those who received information from patients attending pharmacies or who did not receive any information have lower knowledge than those who obtained information from university by $75.4 \%$ and $88.7 \%$, respectively $(\mathrm{OR}=0.246, p=0.044$ and
$\mathrm{OR}=0.113, p=0.05$, respectively). Spending more hours in the pharmacy increases the level of knowledge at a rate of $1.2 \%$ for each hour spent more $(p=0.039)$ (Table 5).

\subsubsection{Logistic regression on pharmacists' attitude toward medicinal cannabis prescription in Lebanon}

Pharmacists located in North province are not in favor of prescribing cannabis, with $90.2 \%$ of them prescribing less than their counterparts who are living in Beirut $(p=0.003)$. Furthermore, those with a $\mathrm{PhD}$ degree refused prescription more than those who received a bachelor's degree $(90.5 \% ; p=0.026)$. Yet those who believe that they are comfortable explaining the efficacy of cannabis to their patients are about five times more likely to favor cannabis prescription than those who do not or are not sure if they will be comfortable $(\mathrm{OR}=4.939, p<0.001)$ (Table 5).

\section{DISCUSSION}

Medical cannabis legalization has been a controversial issue worldwide. Many studies have addressed this topic globally. However, in Lebanon no such survey has been conducted so far. Pharmacists play the sole role in counseling customers about medical cannabis, and there has been no research conducted that assessed the pharmacists' readiness for medical cannabis legalization, so the aim of this study was to understand the community pharmacists' level of knowledge and attitudes regarding this new topic.

Table 5 Binary logistic regression using knowledge scores and attitude toward cannabis prescription in Lebanon for certain indications as the dependent variables

\begin{tabular}{|c|c|c|c|c|c|}
\hline \multirow{2}{*}{ Dependent } & \multirow{2}{*}{ Variables } & \multirow{2}{*}{ OR } & \multicolumn{2}{|c|}{$95 \% \mathrm{CI}$} & \multirow{2}{*}{$p$} \\
\hline & & & Lower & Upper & \\
\hline \multirow[t]{2}{*}{ Dichotomized cannabis global knowledge score ${ }^{\mathrm{a}}$} & Residence (North Lebanon) & 0.082 & 0.010 & 0.671 & $0.02^{*}$ \\
\hline & $\begin{array}{l}\text { Information receiving through university and } \\
\text { personal research }\end{array}$ & 2.497 & 1.064 & 5.856 & $0.035^{*}$ \\
\hline \multirow{3}{*}{ Dichotomized cannabis medical uses score ${ }^{b}$} & Didn't receive any information & 0.105 & 0.012 & 0.935 & $0.043^{*}$ \\
\hline & Years of experience & 1.041 & 1 & 1.083 & 0.052 \\
\hline & North province & 0.057 & 0.006 & 0.516 & $0.011^{*}$ \\
\hline \multirow[t]{3}{*}{ Dichotomized cannabis side effects score ${ }^{c}$} & Working hours per week & 1.010 & 0.998 & 1.023 & 0.1 \\
\hline & Receiving information from news & 0.191 & 0.036 & 1.003 & $0.05^{*}$ \\
\hline & Working hours per week & 1.012 & 1.001 & 1.024 & $0.039^{*}$ \\
\hline \multirow[t]{3}{*}{ Dichotomized cannabis-drug interaction score ${ }^{\mathrm{d}}$} & Receiving information from patients & 0.246 & 0.063 & 0.960 & $0.044^{*}$ \\
\hline & Receiving information from news & 0.113 & 0.013 & 0.996 & $0.05^{*}$ \\
\hline & North province & 0.098 & 0.021 & 0.446 & $0.003^{*}$ \\
\hline \multirow{3}{*}{$\begin{array}{l}\text { Attitude toward cannabis prescription in Lebanon } \\
\text { for certain indications }{ }^{\mathrm{e}}\end{array}$} & $\mathrm{PhD}$ degree & 0.095 & 0.012 & 0.754 & $0.026^{*}$ \\
\hline & Have patients benefiting from cannabis & 2.089 & 0.928 & 4.701 & 0.075 \\
\hline & Comfortable explaining cannabis efficacy & 4.939 & 2.118 & 11.515 & $<0.01^{*}$ \\
\hline
\end{tabular}

a Global knowledge score: Omnibus test $p<0.05$; Hosmer-Lemshow test $p=0.96$, that is, $>0.10$; Nagelkerke $R^{2}=0.135$; overall predicted percentage $=60.9 \%$. Independent variables: residence. ${ }^{b}$ Cannabis medical uses score: Omnibus test $p<0.001$, that is, $<0.05$; Hosmer-Lemshow test $p=0.64$, that is, $>0.10$; Nagelkerke $R^{2}=0.244$; overall predicted percentage $=$ $66.1 \%$. Independent variable: information source, years of experience. ${ }^{c}$ Cannabis side effects score: Omnibus test $p<0.001$, that is, $<0.05$; Hosmer-Lemshow test $p=0.516$, that is,

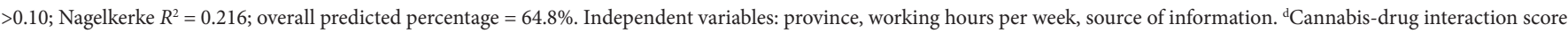
Omnibus test $p<0.05$; Hosmer-Lemshow test $p=0.544$, that is, $>0.10$; Nagelkerke $R^{2}=0.146$; overall predicted percentage $=60.1 \%$. Independent variables: working hours per week, source of information. ${ }^{e}$ Attitude cannabis prescription in Lebanon for certain indications: Omnibus test $p<0.05$; Hosmer-Lemshow test $p=0.575$, that is, $>0.10$; Nagelkerke $R^{2}=0.319$ overall predicted percentage $=81.1 \%$. Independent variables: residence, degree, have patients who may benefit from cannabis, comfortable to explain about cannabis efficacy. ${ }^{*} p<0.05$, level of significance. 
Pharmacists' knowledge about the medical uses of cannabis reached $40.9 \%$ with $58.8 \%$ of them exhibiting good knowledge. Similarly, $51.3 \%$ of Serbian students were familiar with the therapeutic purposes of cannabis [23]. Migraine was highly recognized by many respondents (78\%) as a condition for which cannabis is indicated; in contrast, among US pharmacy students, epilepsy was the most widely known (74\%), whereas cancer and glaucoma are best known among Kansas pharmacy students (91\% and 57\%, respectively) [22]. Lebanese pharmacists failed in identifying the conditions in which cannabis is not permitted to be used such as anxiety, depression, and schizophrenia - that is, only $14 \%, 15 \%$, and $32 \%$, respectively, were able to correctly answer that cannabis is not allowed in these cases. Oppositely, more US pharmacy students recognized that anxiety, depression, and schizophrenia are not targets (91\%, $86 \%$, and $85 \%$, respectively) [30].

This knowledge was affected by how pharmacists received their information. Those who did not receive any information logically showed lower level of knowledge by $89.5 \%$ compared with those who received information from university curriculum, whereas those who acquired further information through personal research had twice better knowledge. Furthermore, experience in pharmacy seems to be a favorable condition for acquiring knowledge.

Knowledge about the side effects of cannabis was $58.1 \%$, with euphoria being the most widely known (80\%). Euphoria and disorientation of time were among the top responses of US pharmacy students at 58\% [30]. However, diarrhea seems to be the least known adverse effect among our sample and US pharmacy students (30\% and $30 \%$, respectively) as there is an erroneous belief that cannabis leads to constipation (63\% and $21 \%$, respectively) [30].

Receiving information from news sources rather than university was an unfavorable condition as pharmacists showed less knowledge by $80.9 \%$. Yet, each hour spent more in the pharmacy is suspected to increase knowledge by $1 \%$.

Cannabis-drug interaction knowledge failed to reach satisfactory levels as knowledge did not exceed $27.64 \%$. There has been no study conducted previously to assess pharmacists' knowledge about cannabis-drug interaction, yet $38.7 \%$ of primary care providers have previously known that medical cannabis has significant interactions with medical therapies [31]. Similarly, Californian pharmacists thought that medical cannabis could have interactions with drugs [25]. Interestingly, only $33.5 \%$ were able to name cannabis components; hence, knowledge about interactions is suspected to be low as many could not even identify what the active substances are.

Cannabis-drug interactions knowledge improves by $1.2 \%$ among those who spend more time in the pharmacy and received information from university. Colorado family physicians who had not recommended cannabis obtained information from news and practice policy sources [32]. Hence, the source of information has an explicit role in formulating ones' knowledge and attitude toward certain topics.

Pharmacists' global knowledge reached $42.45 \%$ with $51.1 \%$ of them considered to have a good knowledge. Most pharmacists mentioned that they obtained information from university (49\%). Meanwhile, majority of Washington health care providers (57\%) declared that they acquired knowledge from news and media sources [28], and more than half of Novi Sad pharmacy students learned from sources other than university [23].

With this poor knowledge level, most pharmacists expressed their desire for more information about all suggested topics. Likewise, most primary care providers were interested in learning more about medical cannabis [31]. Moreover, $93.6 \%$ of Lebanese pharmacists supported the need for further clinical studies, whereas some Australian general practitioners recommended the need for more evidence about its efficacy [24].

The Ministry of Health was considered a trusted source to provide pharmacists with information $(60 \%)$, followed by the Lebanese Order of Pharmacists (58\%). Meanwhile, Minnesota pharmacists ranked the Board of Pharmacists as the most preferred source (62\%) followed by the Minnesota Ministry of Health (23\%) [21]. The most suitable way to obtain this knowledge was through conferences $(63 \%)$ as direct interaction can occur between pharmacists and presenter, whereas Minnesota pharmacists preferred e-mails (56\%) [21].

Most pharmacists heard about medicinal cannabis legalization laws (88\%) and 46\% supported the legalization. Comparably, 59\% of Kansas university students felt that medical marijuana should be legalized in all states [22]. Only 39\% of the Lebanese community pharmacists found that the benefits of using cannabis outweigh the harms and risks associated with its use. Washington health care professionals found that medicinal cannabis can help people with chronic debilitating conditions [28], whereas about half of Australian general practitioners were neutral as to whether there was sufficient overall scientific evidence for the efficacy of medicinal cannabis [24].

By contrast, $57.9 \%$ of Lebanese pharmacists believe that the use of cannabis and its derivatives in therapeutical purposes could lead to their abuse as many declare that some patients exhibit noncompliance especially with "closet medications." Similarly, Washington professionals support this when $61.6 \%$ realized that the most endorsed risk is that cannabis can be addictive and can cause serious mental health risks even if professionals recommend it [28], and $27.7 \%$ of Australian general practitioners will not prescribe it due to the risk of abuse and dependence [24].

More than half of the respondents believe that cannabis explicitly can lead to death. Although this is wrong and many Australian practitioners believe that it is safer than other chemotherapy drugs, opioid analgesics, benzodiazepines, antipsychotics, antidepressants, and statins [24] as it has a negligible mortality rate and low dependence and withdrawal syndrome [33]. Yet this fact is confusing for the pharmacists for the same reason that makes them believe that cannabis can lead to its abuse.

Despite that, $79.4 \%$ of the pharmacists are in favor of allowing cannabis prescription for certain indications in Lebanon and 70\% mentioned that they have patients who can benefit from it. Similarly, more than half of Australian practitioners believe that cannabis should be available on prescriptions and $44 \%$ have patients who can benefit from it [24]. Also, the majority of Minnesota providers assumed that medicinal cannabis is a legitimate medical therapy, and more than one-third believed it should be offered to patients with medical conditions [31]. 
Pharmacists feel comfortable explaining to their patients about cannabis efficacy, side effects, drug interactions, and dosage forms after legalization, and obtaining enough information about it. This is not surprising, as $50 \%$ of Colorado physicians were not ready and did not want to answer patients' questions regarding cannabis [31], whereas $66 \%$ of Washington clinicians with written authorizations to prescribe cannabis were comfortable in doing so [28]. What increases the level of comfort is education programs, clinical data, research proving effectiveness, algorithms for recommending medicinal cannabis, clinical guidelines, and change in the legal status of cannabis [28].

Furthermore, more than half of the pharmacists prefer dispensing medicinal cannabis as a prescription drug; in a parallel trend, Serbian pharmacy students also refused to dispense cannabis as an over-the-counter medication [23].

Only $28.7 \%$ of the pharmacists think that cannabis legalization will have a positive impact on the Lebanese society. More than half believe that illegal consumption will be enhanced, $65.7 \%$ suppose that obtaining cannabis for abuse will be easier, and $82.4 \%$ believe that cannabis dispensing in the pharmacy will expose it to dangers. Yet, $46.8 \%$ think that the price of cannabis will increase after legalization.

This is attributable to the society formulation and experience of pharmacists with non-abidance of laws. Also, those who oppose legalization think that cannabis will have a negative impact on the society, as illustrated by previous findings in Iceland showing that those who support legalization expected a positive impact on the society whereas those who do not believe so expected the opposite result [29]. Results regarding consumption are consistent with many studies that showed an increase in cannabis consumption upon legalization [34-36]. Easier purchasing of cannabis for abuse will occur because of fake prescriptions. The large number of pharmacists who believe that dispensing in pharmacies can lead to problems highly surpasses that reported in Serbians (33.8\%) [23]. This is because of the lack of security in Lebanon.

Notably, the pharmacists' attitude toward the legality of prescribing cannabis is affected by residence, academic degree, and comfortability in explaining cannabis efficacy. No association with sex, age, and years of experience was comparable to what was found among Colorado family physicians [32]. However, age and level of education seemed to be in contrast with Icelandic people's attitude toward legalization, whereas male sex is a favorable factor for legalization [29].

Lastly, only $4 \%$ of the pharmacists declared that they have consumed cannabis. This low percentage is in obvious contrast to that reported among Colorado physicians (20\%) [32] and Kansas pharmacy students (37\%) [22]. This could be attributable to the sensitive nature of this topic in our society along with the fact that we conducted face-to-face interviews, which are less comfortable for respondents who are answering such types of questions.

This study has several limitations, which include the small sample size because of the short period of data collection. Moreover, a convenient sample is generally unfavorable especially as participants were recruited mainly from two Lebanese provinces. However, participants who were from different Lebanese regions helped increase the representativeness of our sample.

Our study is the first of its kind to be conducted in Lebanon. As this is a new topic of debate in our country, there was a need for such scientific work. The questionnaire was well structured in terms of the analyzed knowledge score, which showed a remarkably good reliability and underwent a factor analysis. No previous studies assessed the knowledge and attitude of Lebanese pharmacists toward this topic. Further studies are required to increase our knowledge about medicinal cannabis.

\section{CONCLUSION}

Medical cannabis legalization has been a controversial issue worldwide. In Lebanon, pharmacists' knowledge about it is still weak and requires further development in order to allow them to manage its presence in pharmacies. Although pharmacists are highly concerned about medical cannabis misuse, they do support its legalization for therapeutic purposes. Further educational strategies should be implemented to increase knowledge among the entire Lebanese population.

\section{CONFLICTS OF INTEREST}

The authors declare they have no conflicts of interest.

\section{AUTHORS' CONTRIBUTION}

DK contributed in study conceptualization. LHJ contributed in data curation. LHJ and NL contributed in formal analysis. LHJ, NL, SZ, SA and DK contributed in methodology. DK contributed in project administration. DK, NL and SZ contributed in supervision. LHJ contributed in writing (original draft) the manuscript. DK and $\mathrm{NL}$ in writing (review and editing) the manuscript.

\section{ABBREVIATIONS}

CBD, cannabidiol; CBN, cannabinol; CI, confidence interval; OR, odds ratio; SD, standard deviations; SPSS, Statistical Package for the Social Sciences; THC, $\Delta-9$ tetrahydrocannabinol.

\section{REFERENCES}

[1] Madras BK. Update of cannabis and its medical use. In: Proceedings of the 37th meeting of the Expert Committee on Drug Dependence, Agenda item 6.2. Geneva, Switzerland: World Health Organization; 2015. Available from: https://www.who.int/ medicines/access/controlled-substances/6_2_cannabis_update. pdf (accessed May 6, 2020).

[2] Gloss D. An overview of products and bias in research. Neurotherapeutics 2015;12:731-4.

[3] Hurd YL, Yoon M, Manini AF, Hernandez S, Olmedo R, Ostman $\mathrm{M}$, et al. Early phase in the development of cannabidiol as a treatment for addiction: opioid relapse takes initial center stage. Neurotherapeutics 2015;12:807-15.

[4] World Health Organization (WHO). Cannabidiol (CBD) critical review report. Proceedings of the 40th meeting of the Expert Committee on Drug Dependence. Geneva, Switzerland: World Health Organization; 2018. Available from: https:/www.who.int/ medicines/access/controlled-substances/WHOCBDReport May2018-2.pdf?ua=1 (accessed May 6, 2020). 
[5] World Health Organization (WHO). The health and social effects of non-medical cannabis use. Geneva, Switzerland: World Health Organization; 2016. Available from https://apps.who.int/ iris/bitstream/10665/251056/1/9789241510240-eng.pdf?ua=1 (accessed May 6, 2020).

[6] National Academies of Sciences, Engineering, and Medicine. The health effects of cannabis and cannabinoids: the current state of evidence and recommendations for research. Washington, DC: The National Academies Press; 2017.

[7] Danielsson AK, Falkstedt D, Hemmingsson T, Allebeck P, Agardh E. Cannabis use among Swedish men in adolescence and the risk of adverse life course outcomes: results from a 20 year follow-up study. Addiction 2015;110:1794-802.

[8] Fergusson DM, Boden JM. Cannabis use and later life outcomes. Addiction 2008;103:969-78.

[9] Fergusson DM, Boden JM, Horwood LJ. Psychosocial sequelae of cannabis use and implications for policy: findings from the Christchurch Health and Development Study. Soc Psychiatry Psychiatr Epidemiol 2015;50:1317-26.

[10] Battala A, Bhattacharyya S, Yücel M, Fusar-Poli P, Crippa JA, Nogué S, et al. Structural and functional imaging studies in chronic cannabis users: a systematic review of adolescent and adult findings. PLoS One 2013;8;e55821.

[11] Sorensen CJ, DeSanto K, Borgelt L, Phillips KT, Monte AA. Cannabinoid hyperemesis syndrome: diagnosis, pathophysiology, and treatment-a systematic review. J Med Toxicol 2017;13:71-87.

[12] Retail Marijuana Public Health Advisory Committee. Monitoring health concerns related to marijuana in Colorado: changes in marijuana use patterns, systematic review, and possible marijuanarelated health effects. Colorado, USA: Colorado Department of Public Health and Environment; 2016, Available from https:// www.colorado.gov/pacific/cdphe/retail-marijuana-publichealth-advisory-committee (accessed May 6, 2020).

[13] Franz CA, Frishman WH. Marijuana use and cardiovascular disease. Cardiol Rev 2016;24:158-62.

[14] Hall W. What has research over the past two decades revealed about the adverse health effects of recreational cannabis use? Addiction 2015;110:19-35.

[15] European Monitoring Center for Drugs and Drugs Addiction. Medical use of cannabis and cannabinoids: questions and answers for policy making. Luxembourg: Publications Office of the European Union; 2018.

[16] United Nations Office of Drug and Crime. Analysis of drug markets. Opiates, cocaine, cannabis, synthetic drugs. Vienna: United Nations Publication; 2018.

[17] Iversen LL. The science of marijuana. 2nd ed. Oxford, UK: Oxford University Press; 2008, p. 273.

[18] Russo EB. Taming THC: potential cannabis synergy and phytocannabinoid-terpenoid entourage effects. Br J Pharmacol 2011;163:1344-64.

[19] Uritsky TJ, McPherson ML, Pradel F. Assessment of hospice health professionals' knowledge, views, and experience with medical marijuana. J Palliat Med 2011;14:1291-5.
[20] Adler JN, Colbert JA. Clinical decisions. Medicinal use of marijuana-polling results. N Engl J Med 2013;368:e30.

[21] Hwang J, Arneson T, St Peter W. Minnesota pharmacists and medical cannabis: a survey of knowledge, concerns, and interest prior to program launch. P T 2016;41:716-22.

[22] Moeller KE, Woods B. Pharmacy students' knowledge and attitudes regarding medical marijuana. Am J Pharm Educ 2015;79:85.

[23] Stojanović M, Tomas A, Paut-Kusturica M, Rašković A, Ubavić $\mathrm{M}$, Tomić Z, et al. Pharmacy students' knowledge and attitudes regarding cannabis for medical purposes. Hosp Pharmacol 2017;4:559-67.

[24] Karanges EA, Suraev A, Elias N, Manocha R, McGregor IS. Knowledge and attitudes of Australian general practitioners towards medicinal cannabis: a cross-sectional survey. BMJ Open 2018;8;e022101.

[25] Szyliowicz D, Hilsenrath P. Medical marijuana knowledge and attitudes: a survey of the California pharmacists association. J Prim Care Community Health 2019;10:1-6.

[26] Hilal N, Bou-Karroum L, Ataya N, El-Jardali F. K2P rapid response: legalizing cannabis cultivation: what we need to know \& is Lebanon ready? Beirut, Lebanon: Knowledge to Policy (K2P) Center; 2018.

[27] Al Joumhouria; 2018. Available from: https://www.aljoumhouria.

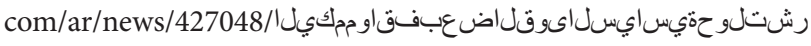
تشيش حلاةعارزعي (accessed May 9, 2020).

[28] Carlini BH, Garrett SB, Carter GT. Medicinal cannabis: a survey among health care providers in Washington State. Am J Hosp Palliat Med 2017;34:85-91.

[29] Kristinsdóttir S. Attitudes towards cannabis legalization in Iceland. Iceland: Reykjavik University; 2016. Available from https://skemman.is/bitstream/1946/25686/2/BSc\%20research\% 20assignment\%20Final1.pdf (accessed May 6, 2020).

[30] Caligiuri FJ, Ulrich EE, Welter KJ. Pharmacy student knowledge, confidence and attitudes toward medical cannabis and curricular coverage. Am J Pharm Educ 2018;82:6296.

[31] Philpot LM, Ebbert JO, Hurt RT. A survey of the attitudes, beliefs and knowledge about medical cannabis among primary care providers. BMC Fam Pract 2019;20:17.

[32] Kondrad E, Reid A. Colorado family physicians' attitudes toward medical marijuana. J Am Board Fam Med 2013;26:52-60.

[33] Nutt D, King LA, Saulsbury W, Blakemore C. Development of a rational scale to assess the harm of drugs of potential misuse. Lancet 2007;369:1047-53.

[34] Miech RA, Johnston L, O’Malley PM, Bachman JG, Schulenberg J, Patrick ME. Trends in use of marijuana and attitudes toward marijuana among youth before and after decriminalization: the case of California 2007-2013. Int J Drug Policy 2015;26:336-44.

[35] Palamar JJ, Ompad DC, Petkova E. Correlates of intentions to use cannabis among US high school seniors in the case of cannabis legalization. Int J Drug Policy 2014;25:424-35.

[36] Weatherburn D, Jones C, Donnelly N. Prohibition and cannabis use in Australia: a survey of 18 to 29-year-olds. Aust N Z J Criminol 2003;36:77-93. 